SHORT REPORT

\title{
Sex differences and lateral asymmetry in heart rate modulation in patients with temporal lobe epilepsy
}

\author{
A Kirchner, E Pauli, M J Hilz, B Neundörfer, H Stefan
}

J Neurol Neurosurg Psychiatry 2002;73:73-75

This study was designed to study the influence of gender and lateral hemispheric asymmetry on heart rate modulation during temporal lobe seizures. Heart rate was recorded during complex partial seizures in 10 female and 11 male patients ( 12 with a right temporal lobe focus, nine with a left focus), with simultaneous video monitoring and bilateral subdural electrode placement. Heart rate changes were analysed during the seizure, at a time when the epileptic activity was restricted to one hemisphere. In this analysed interval, the heart rate of patients with a right temporal lobe focus showed a significant increase, from 73.5 to 91.0 beats $/ \mathrm{min} \quad(F=10.7, \mathrm{df}=2.3 / 27$, $\mathrm{p}<0.001$ ), while the heart rate of patients with a left sided focus only increased slightly, from 77.0 to 82.5 beats/min (NS). An effect of sex was demonstrated, in that the influence of focus laterality could only be shown in male patients $(F=14.24, d f=2.58 / 27, p<0.001)$. These results confirm the right hemispheric lateralisation of sympathetic cardiac control in male patients.

E pileptic seizures, especially those originating from the temporal lobe, are often associated with abnormalities of the ECG. ${ }^{1-5}$ As certain anatomical structures in the temporal lobe, like the insula and the amygdala, play an important role in autonomic cardiovascular regulation, ${ }^{67} \mathrm{epi}-$ leptic discharges in these structures may lead to heart rate changes that can precede other clinical symptoms by more than a minute. ${ }^{8}$

Whether there is a central hemispheric lateralisation of cardiac autonomic control is debatable. Evidence for a predominantly sympathetic influence of the right cerebral hemisphere comes from several studies investigating epileptic patients undergoing intracarotid amobarbital sodium test ${ }^{910}$ and from stimulation experiments of the right insular cortex in patients undergoing surgical treatment for epilepsy. ${ }^{12}$ On the other hand, several studies assessing ECG changes during epileptic seizures have failed to prove a relation between the incidence or quality of cardiac arrhythmias and the side of the epileptic focus. ${ }^{313} 14$

To clarify the question of whether there is a central imbalance in cardiac autonomic control, we analysed early ictal heart rate changes during temporal lobe seizures monitored using bilateral subdural electrodes.

\section{METHODS}

We studied 21 patients with unilateral temporal lobe epilepsy-12 with a right temporal focus and nine with a left-who were referred to the Epilepsy Centre of the University of Erlangen-Nuremberg for presurgical evaluation and scheduled as candidates for surgery. None of the subjects suffered from cardiovascular disease. The characteristics of the patients and the aetiologies of their epilepsy are given in table 1 .
Table 1 Sex, age, and aetiology of the epilepsy in patients with temporal lobe epilepsy

\begin{tabular}{lll}
\hline & Left TL & Right TL \\
\hline Men & 5 & 6 \\
Women & 4 & 6 \\
Age (years) (mean (SD)) & $29(9)$ & 34 (8) \\
Aetiology & & \\
$\quad$ Hippocampal sclerosis (HS) & 6 & 2 \\
$\quad$ Focal neoplasm & 2 & 1 \\
$\quad$ Dual (HS and hamartoma, HS and & 1 & 7 \\
migration disorder) & - & 2 \\
$\quad$ Kryptogenic & & \\
\hline TL, temporal lobe. & &
\end{tabular}

All patients underwent seizure monitoring using bilateral subdural electrodes, including bilateral temporal strip electrodes or bitemporal grid electrodes.

We analysed the first recorded seizure in each patient. Heart rate was averaged manually over five second intervals. The first clinical symptom, which could include sensing an aura, was defined as the seizure onset. The time period from $35 \mathrm{sec}-$ onds before to five seconds after clinical seizure onset was used for statistical analysis. This interval was chosen because no epileptic discharges had occurred before this time within the period of study, the epileptic activity was restricted to one temporal lobe, and there was interhemispheric propagation in nearly all recorded seizures after this period.

\section{Statistical analysis}

Statistical significance was assumed at a probability ( $p$ ) value of $<0.05$. All data are presented as means (SD). To analyse changes in heart rate before and during the seizures in relation to focus lateralisation and sex, an analysis of variance for repeated measures (MANOVA for repeated measurements) was employed, with focus laterality and sex as betweensubject factors and the five second time intervals before and after seizure onset as repeated measures. The KolmogorovSmirnov statistic with a Lilliefors significance level for testing normality was employed. Mauchly's test of sphericity was used to test the hypothesis that the covariance matrix of the transformed variables has a constant variance on the diagonal and zeros off the diagonal. There was no evidence to reject the normality assumption. In case of violation of the sphericity assumption, the Greenhouse-Geisser correction was employed. In case of significant $F$ values, separate analyses for both focus and sex were computed. Heart rate differences in the time course were analysed using polynomial contrasts (general linear model; within-subject contrasts).

\section{RESULTS}

In the interval analysed ( $-35 \mathrm{~s}$ to $+5 \mathrm{~s})$, mean (SD) heart rate increased from 77.0 (19.5) to 82.5 (17.8) beats/min in patients with a left sided focus, and from 73.5 (12.3) to 91.0 (16.1) beats/min in those with a right sided focus. 


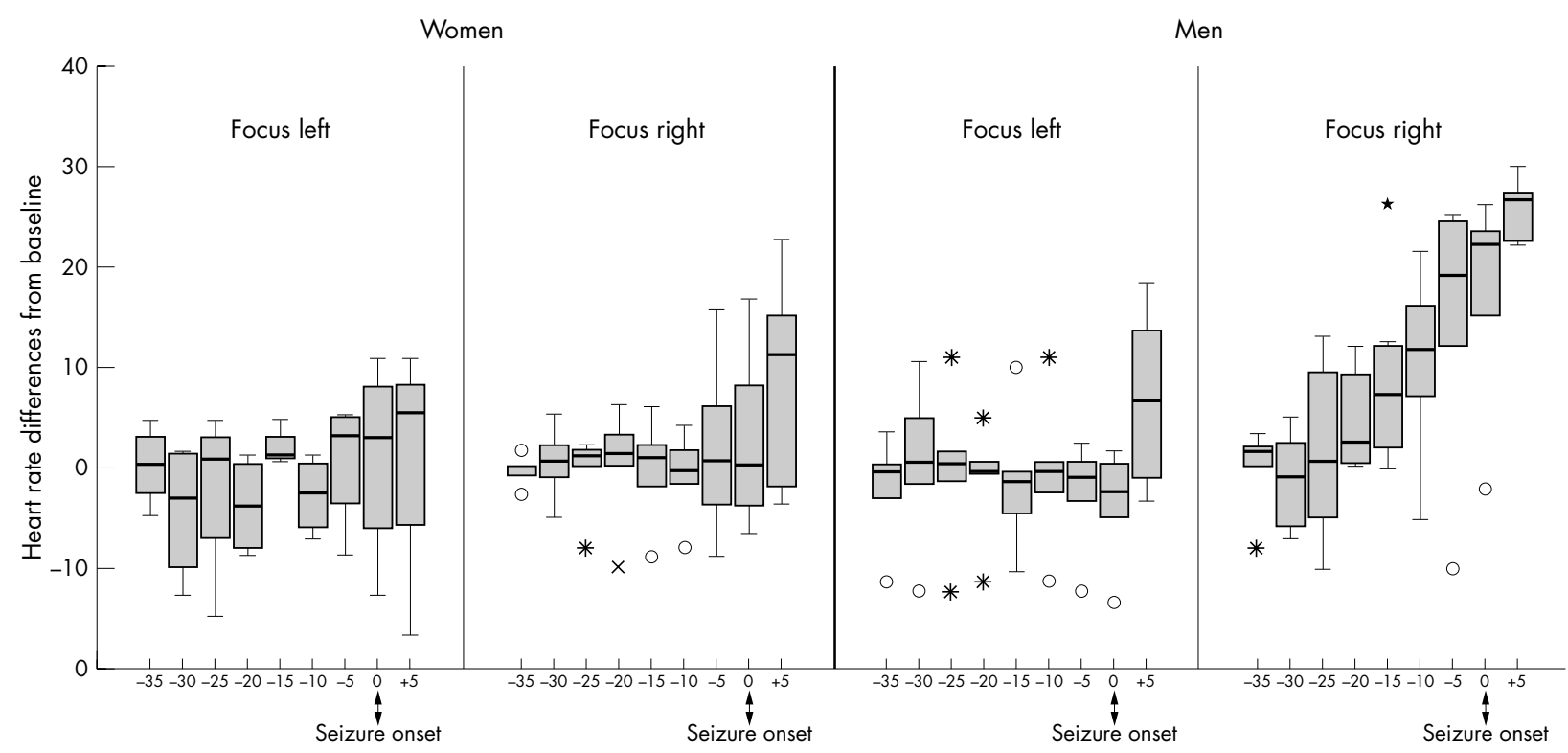

Figure 1 Heart rate changes in women and men during temporal lobe seizures in the time period of unilateral epileptic activity (from $35 \mathrm{~s}$ before to $5 \mathrm{~s}$ after clinical seizure onset). Outliers are shown as stars.

MANOVA revealed a significant interaction for time points $\times$ focus lateralisation $(\mathrm{F}=3.8, \quad \mathrm{df}=2.89 / 27, \quad \mathrm{p}=0.017$, Greenhouse-Geisser corrected). Further separate analysis for each focus group showed an increase in heart rate in the right temporal group $(\mathrm{F}=10.7, \mathrm{df}=2.34 / 27, \mathrm{p}<0.001$, Greenhouse-Geisser corrected); the polynomial contrast showed a significant linear trend $(\mathrm{F}=17.45, \mathrm{df}=1 / 11$, $\mathrm{p}=0.002$, Greenhouse-Geisser corrected). In the left temporal group no significant change was observed.

We also found an interaction for time points $\times$ focus lateralisation $\times \operatorname{sex}(\mathrm{F}=3.67, \mathrm{df}=2.89 / 27, \mathrm{p}=0.019)$, showing a significant effect of sex. Separate analyses for both sexes showed a linear increase in heart rate only in male patients with a right temporal seizure onset $(\mathrm{F}=14.24, \mathrm{df}=2.58 / 27$, $p=0.001$; Greenhouse-Geisser corrected). Neither in male patients with a left hemispheric seizure onset nor in any female patient subgroup was seizure onset associated with heart rate changes (fig 1 ).

\section{DISCUSSION}

Our results suggest that the hemispheric influence on autonomic cardiovascular regulation is lateralised in men, as male patients with a right temporal lobe seizure onset had a significantly greater increase in heart rate early in the course of the seizure. Neither male patients with left temporal epileptic focus nor any female patients showed significant changes in heart rate. By restricting our analysis to seizures monitored by bilateral invasive electrodes, we were able to show that during the investigated period the epileptic activity was strictly confined to one hemisphere. Thus spreading of the epileptic activity could be ruled out as a cause of the observed heart rate effects.

Our results are somewhat at variance with earlier studies investigating ictal ECG modulation. In general, no relation was found in those studies between the site of the epileptic seizure and the type of autonomic response. ${ }^{3513}$ Methodological differences may have contributed to this discrepancy-for example, the use of a restricted number of scalp electrodes in some studies may have made it hard to identify primary and propagated ictal features. This is important in that heart rate changes can be the earliest symptom of a seizure in temporal lobe epilepsy. ${ }^{8}$ Thus the fact that most earlier reports involved the use of only a limited number of scalp electrodes ${ }^{1-3}{ }^{14}$ might well have contributed to the discrepant findings. Nevertheless, Epstein et al also used subdural and bilateral temporal lobe depth electrodes and obtained results that differed from ours; they concluded that ictal tachycardia depended only on the volume of cerebral structures recruited into the seizure, regardless of the seizure origin or the cerebral structures involved. ${ }^{13}$

Several things may have contributed to this disagreement. First, Epstein et al disregarded sex differences. Second, only five patients were investigated (though with a total of 27 seizures); however, as there is evidence from published reports that heart rate profiles show noticeable seizure to seizure similarities when multiple fits are recorded in the same patient, ${ }^{15}$ an analysis of many seizures from a small number of patients will not necessarily increase the weight of the results.

The hypothesis of an autonomic cerebral lateralisation has been proposed by other investigators. For example, intraoperative stimulation of the insular cortex in humans was found to lead to differential left/right heart rate changes, with tachycardia produced by stimulation of the right side. ${ }^{12}$

Additional support for cerebral lateralisation of the sympathetic cardiovascular input is obtained from studies using the amobarbital test (WADA test). Zamrini et al found a significant bradycardia after inactivation of the right hemisphere and tachycardia after inactivation of the left hemisphere. ${ }^{10}$ Another investigation produced similar results when performing spectral analysis of heart rate, and confirmed a predominance of the right hemisphere in the sympathetic regulation of cardiovascular function. ${ }^{9}$

Another major finding of our study was a central imbalance of autonomic cardiac control in men only. From published reports there is evidence for sex differences in cardiac sympathovagal regulation. It is not yet clear whether there are sex differences in the incidence of sudden epileptic death, ${ }^{16}{ }^{17}$ or if there are, whether this syndrome is caused by central apnoea rather than by central autonomic deregulation. ${ }^{18}$ However, heart rate variability in women has been shown to be significantly less than in men as a result of reduced sympathetic influence on the heart, ${ }^{19}$ a fact that could explain why women appear to have a lower incidence of atrial fibrillation and sudden cardiac death than men. ${ }^{20} 21$ Our results suggest that a dissimilar central regulation may contribute to these sex differences in heart rate variability. Interestingly, lateralisation of cortical function in men has also been shown 
for another central function: in imaging studies of central language processing it was found that cortical activation was restricted to the left hemisphere in men, whereas in women there was a tendency to bilateral brain activation. ${ }^{22}$

Although our results may be considered preliminary, owing to the rather small sample size, the findings confirm a central lateralisation of autonomic cardiovascular regulation in men.

\section{ACKNOWLEDGEMENTS}

We wish to thank Dr Y Saleh for helpful cooperation. This work was supported by the Glaxo-Wellcome grant for clinical epilepsy research 1999 and presented at the WCN 2001, London.

\section{Authors' affiliations}

A Kirchner, E Pauli, M J Hilz, B Neundörfer, H Stefan, Department of Neurology, University of Erlangen-Nuremberg, Erlangen, Germany

Correspondence to: Dr Annette Kirchner, Neurologische Klinik der FAU-Erlangen/Nürnberg, Schwabachanlage 6, D-91054 Erlangen, Germany; annette.kirchner@neuro.imed.uni-erlangen.de

Received 11 July 2001

In revised form 11 March 2002

Accepted 12 March 2002

\section{REFERENCES}

1 Blumhardt LD, Smith PE, Owen L. Electrocardiographic accompaniments of temporal lobe epileptic seizures. Lancet 1986;i:1051-6.

2 Keilson MJ, Hauser WA, Magrill JP. Electrocardiographic changes during electrographic seizures. Arch Neurol 1989;46:1169-70.

3 Galimberti CA, Marchioni E, Barzizza F, et al. Partial epileptic seizures of different origin variably affect cardiac rhythm. Epilepsia 1996;37:742-7

4 Stefan H, Carter Snead O. Absence seizures. In: Engel J, Pedley TA, eds. Epilepsy - a comprehensive textbook. Philadelphia: Lipincott-Raven 2000:579-90.

5 Nei $M$, Ho RT, Sperling MR. EKG abnormalities during partial seizures in refractory epilepsy. Epilepsia 2000;41:542-8.

6 Oppenheimer SM, Saleh P, Cechetto DF. Lateral hypothalamic neurotransmission and neuromodulation on the specific cardiac effects of insular cortex stimulation. Brain Res 1992;581:133-42.
7 Gelsema AJ, McKitrick DJ, Calaresu FR. Cardiovascular responses to chemical and electrical stimulation of amygdala in rats. Am J Physiol 1987;253:R712-8.

8 Saleh Y, Kirchner A, Pauli E, et al. Temporal lobe epilepsy: effect of focus side on the autonomic regulation of heart rate? Nervenarz $t$ 2000;71:477-80

9 Yoon BW, Morillo CA, Cechetto DF, et al. Cerebral hemispheric lateralization in cardiac autonomic control. Arch Neurol 1997;54:741-4.

10 Zamrini EY, Meador KJ, Loring DW, et al. Unilateral cerebral inactivation produces differential left/right heart rate responses. Neurology 1990;40:1408-11.

11 Hilz MJ, Dutsch M, Perrine K, et al. Hemispheric influence on automatic modulation and baroreflex sensitivity. Annals of Neurology 2001;49:575-84.

12 Oppenheimer SM, Gelb A, Girvin JP, et al. Cardiovascular effects of human insular cortex stimulation. Neurology 1992;42:1727-32.

13 Epstein MA, Sperling MR, O'Connor M. Cardiac rhythm during temporal lobe seizures. Neurology 1992;42:50-3.

14 Rossi E, Rossi GF. Heart rate behaviour during partial epileptic seizures: an electroclinical study. In: Stober T, Schimrik K, et al, eds. Central nervous system control of the heart. Boston: Kluver Academic, 1986:187-201.

15 Smith PE, Howell SJ, Owen L, et al. Profiles of instant heart rate during partial seizures. Electroencephalogr Clin Neurophysiol 1989;72:207-17.

16 Lhatoo SD, Johnson AL, Goodridge DM, et al. Mortality in epilepsy in the first to 14 years after diagnosis: multivariate analysis of a long-term, prospective, population based cohort. Ann Neurol 2001;49:336-44.

17 Leestma JE, Walczak T, Hughes JR, et al. A prospective study on sudden unexpected death in epilepsy. Ann Neurol 1989;26:195-203.

18 Langan Y, Nashef L, Sander JW. Sudden unexpected death in epilepsy: a series of witnessed deaths. J Neurol Neurosurg Psychiatry 2000;68:211-13.

19 Ramaekers D, Ector $H$, Aubert $A E$, et al. Heart rate variability and heart rate in healthy volunteers. Is the female autonomic nervous system cardioprotective? Eur Heart J 1998;19:1334-41

20 Verrier RL, Thompson PL, Lown B. Ventricular vulnerability during sympathetic stimulation: role of heart rate and blood pressure. Cardiovasc Res 1974;8:602-10.

21 Larsen JA, Kadish $\mathrm{AH}$. Effects of gender on cardiac arrhythmias. J Cardiovasc Electrophysiol 1998;9:655-64.

22 Shaywitz BA, Shaywitz SE, Pugh KR, et al. Sex differences in the functional organization of the brain for language. Nature 1995;373:607-9. 